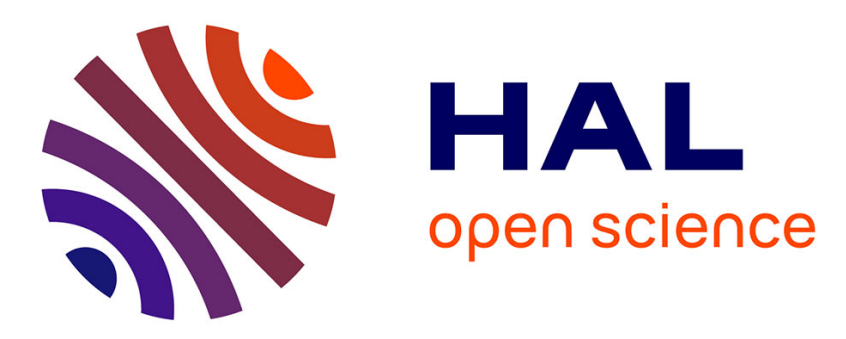

\title{
Synergistic effects of temperature and plant quality, on development time, size and lipid in Eccritotarsus eichhorniae
}

Mohannad Ismail, Margot B Brooks, Joan van Baaren, Loulou Albittar

\section{- To cite this version:}

Mohannad Ismail, Margot B Brooks, Joan van Baaren, Loulou Albittar. Synergistic effects of temperature and plant quality, on development time, size and lipid in Eccritotarsus eichhorniae. Journal of Applied Entomology, 2021, 145 (3), pp.239-249. 10.1111/jen.12841 . hal-03095738

\section{HAL Id: hal-03095738 \\ https://hal.science/hal-03095738}

Submitted on 2 Feb 2021

HAL is a multi-disciplinary open access archive for the deposit and dissemination of scientific research documents, whether they are published or not. The documents may come from teaching and research institutions in France or abroad, or from public or private research centers.
L'archive ouverte pluridisciplinaire HAL, est destinée au dépôt et à la diffusion de documents scientifiques de niveau recherche, publiés ou non, émanant des établissements d'enseignement et de recherche français ou étrangers, des laboratoires publics ou privés. 
1 Synergistic effects of temperature and plant quality, on development time, size and lipid

2 in Eccritotarsus eichhorniae

3

4 Mohannad Ismail ${ }^{1,2^{*}}$, Margot Brooks ${ }^{3}$, Joan van Baaren ${ }^{4}$, Loulou Albittar ${ }^{2}$

5

61 Department of Zoology and Entomology, Rhodes University, Grahamstown, South Africa.

72 Department of Biochemistry and Microbiology, Rhodes University, Grahamstown, South 8 Africa.

93 UMR-CNRS 6553 EcoBio, Université de Rennes 1, France.

104 Earth and Life Institute, Biodiversity Research Centre, UCLouvain, Louvain-la-Neuve 1348,

11 Belgium.

12

$13 *$ Corresponding author

14 Earth and Life Institute, Biodiversity Research Centre, UCLouvain, Louvain la neuve 1348,

15 Belgium

16 E-mail: mohannad.ismail1@gmail.com

17 


\section{Abstract}

Body size is an important biotic factor in evolutionary ecology, since it affects all aspects of insect physiology, life history, and consequently, fitness in ectothermic insects and how species adapt with their environment. It has been linked to temperature, with lower temperatures resulting in larger size. In this study, we tested the combined impact of temperature and plant quality on the body size, and development time from egg to adult of Eccritotarsus eichhorniae (Hemiptera: Miridae), an herbivorous insect used as a biological control agent against the invasive aquatic weed, water hyacinth Eichhornia crassipes (Pontederiaceae). We quantified insect size in individuals exposed to three temperatures $\left(20^{\circ}, 25^{\circ}\right.$ and $\left.30^{\circ} \mathrm{C}\right)$ combined with three qualities of host plant (high, medium and low) by calculating development time and measuring four traits: tibia length, forewing length, dry body mass and lipid content, and we also determined the wing loading index. The development time, dry body mass and lipid content decreased linearly with increasing temperature and decreasing plant quality. The decrease in size was the greatest when high temperature interacted with low plant quality. Smaller individuals had proportionately less lipid content. Wing loading decreased significantly with lower quality of host plant, resulting in individuals likely to have theoretically higher flight ability. The results support the temperature-size rule (TSR) and that plant quality could influence the relationship between development time and the TSR. Results also provide novel evidence for a possible food quality-size rule for both sexes.

Key words: absolute energy demand, dispersal, interaction, mirid, size 


\section{INTRODUCTION}

The capacity of ectothermic insects to establish in specific environments depends on their abundance and distribution, and this is to some extent governed by the abiotic and biotic factors of the environment, and to a large extent by phenotypic plasticity with respect to life history traits and fitness of the insect individuals (Gaston \& Lawton, 1988; Chown \& Terblanche, 2006; Beukeboom, 2018). The fitness of an insect is a function of individual survivorship and fecundity in the environment in which it lives (Mitchell, 1981). Fitness traits have been positively linked to the size of individuals under normal, non-stressful conditions, implying that bigger individuals have higher reproductive outputs (Stearns, 1992; Chown \& Gaston, 2010). Examples of this relationship have been demonstrated in insect parasitoids for both females (Ellers et al., 1998) and males (Lacoume et al., 2006). Body size affects all aspects of physiology and biological processes (Stearns, 1992; Honek, 1993; Kingsolver \& Huey, 2008), thus it is a key consideration in ecology and evolutionary theories (Kraushaar \& Blanckenhorn, 2002; Angilletta et al., 2004). Larger body size is known to be associated with greater protein and lipid reserves (Roff, 1992; Visser, 1994; Rivero \& West, 2002). In insects, lipids are necessary to sustain all biological functions (Arrese \& Soulages, 2010) including reproductive processes (Blanckenhorn et al., 2007; Ismail et al., 2010) and flight activities (Haunerland, 1997), therefore lipid availability is a major factor affecting insect viability.

Temperature is considered as the most important abiotic factor affecting growth, development and nutritional content of hosts and thus determining body size in ectothermic insects (Stamp, 1993; Kingsolver et al., 2004; Stillwell et al., 2007; Mega, 2014). Temperature is also known to affect the relationship between lipid and insect size, thus affecting fitness (de Kogel et al., 1999; Ismail et al., 2012). The relationship between body size and temperature leads to an important premise in insect biology, referred to as the temperature-size rule (TSR). Individuals reared at lower temperature present longer development time and larger body size at maturity 
(Atkinson, 1994; Atkinson \& Sibly, 1997; Blanckenhorn, 1999; Angilletta \& Dunham, 2003). In addition, temperature may have a significant effect on the overall wing loading (the pressure exerted by the wings on the surrounding air) of individuals (Marden \& Chai, 1991; Gilchrist \& Huey, 2004). This index is important because wing loading has been shown to be correlated to flight capacity in some insect species (Moiroux et al., 2010; Gilchrist \& Huey, 2004).

However, in the environment, several factors interact together to affect the development of organisms (Sulmon et al., 2015). For example the availability, as well as the quality, of food are considered to be determinant for several biological parameters of insects (Nylin \& Gotthard, 1998; Awmack \& Leather, 2002; Ismail et al., 2017), including adult body size (Blanckenhorn, 1998; Bownes et al., 2013). Bownes et al. (2013) showed by measuring body mass that body size of the grasshopper Cornops aquaticum (Orthoptera: Acrididae) was bigger when fed on Eichhornia crassipes (Pontederiaceae) plants of higher quality, but did not investigate the effect of temperature. Plant quality is dependent on the levels of available nitrogen (Hogendorp et al., 2006; Burke et al., 2014), but this can also be modified by the temperature of the environment (Bauerfeind \& Fischer, 2013). The interaction between temperature and plant quality has previously been considered in the attempt to understand the impact of plant quality on modulating the relationship between temperature and body size in ectothermic insects and other organisms. For instance, Mascalux et al. (2009) demonstrated the significant effects of temperature and food quality on the clutch size and growth rate of two freshwater cladocerans, Daphnia magna and Simocephalus vetulus (Cladocera: Daphniidae). Lee et al. (2015) found that the reaction norm between temperature and body size of Spodoptera litura (Lepidoptera: Noctuidae) was altered because of changes in food nutrients.

However, most of the studies on the effect of plant quality on TSR have been conducted using different species of plants rather than by varying the quality of the same plant. For instance, Diamond and Kingsolver (2010) evaluated the impact of plant quality on the TSR using the 
insect Manduca sexta (Lepidoptera: Sphingidae) on tobacco and devil's claw. In their study, the two proposed plants might not have had the same relative suitability as resources for the particular herbivore insect, despite being of similar quality (Musundire et al., 2012). To our knowledge, no previous study investigated using differing qualities of the same plant species. In this study, we used the leaf sap-sucking mirid insect Eccritotarsus eichhorniae (Hemiptera: Miridae) as a research model. This insect is native to Peru and was previously named Eccritotarsus catarinensis (Hill et al., 2000), as it was originally considered to be one of two populations (the other originating from Brazil) of the species E. catarinensis (Hill et al., 1999), due to their almost undistinguishable morphologies. However, Paterson et al. (2016) confirmed that they are cryptic species and more recently, Henry (2017) described the Peruvian population as E. eichhorniae. The two species were released in South Africa to control the invasive aquatic weed, E. crassipes, commonly known as the water hyacinth (Hill et al., 1999, 2000). Adults and nymphs of Eccritotarsus feed gregariously on the leaves of water hyacinth, but Paterson et al. (2019) demonstrated that E. eichhorniae can inflict greater damage on plants than $E$. catarinensis, by removing more chlorophyll. Ismail and Brooks (2016) had earlier demonstrated that E. eichhorniae (referred to as the Peruvian strain of E. catarinensis) was able to reproduce at higher temperature compared to the Brazilian species E. catarinensis. The two species have the same upper thermal thresholds, but the lower thermal thresholds are lower for E. catarinensis than for E. eichhorniae (Paterson et al., 2019).

The objective in the present study was to evaluate the impact of temperature and plant quality, and their interaction, on morphological and physiological traits of E. eichhorniae. In order to understand what impact plant quality would have on the relationship between temperature and size, plant quality was manipulated to provide high, medium and low nutritional status. We predicted that: 1) According to the TSR, individuals exposed to low temperature should present a larger body size at maturity and would have greater lipid content than those raised at high 
116 temperatures. 2) Individuals raised on high quality food would be bigger, accumulate more

117 lipids and have higher wing loading compared to those reared on low quality plants. 3) The

118 insect size would decrease linearly with increasing temperature and reduced plant quality. 4)

119 The combination of increased temperature with reduced plant quality would be more

120 detrimental and negative effects would be synergetic, lipid content would be lower and insect

121 body size would be smaller than when exposed to one of these factors alone. 5) Changes in

122 relative size would subsequently affect the overall wing loading.

\section{MATERIALS AND METHODS}

Eccritotarsus eichhorniae used in this study were from a stock culture originally collected from

126 a tropical area in the upper Amazonian basin of the Yarapa River, near Iquitos in Peru (Hill et al., 2000). The insects were reared and maintained at Waainek Mass Rearing Facility (around 2013 around 200 nymphs and adults of E. eichhorniae were taken from a stock population and a new colony established at the department. In the present study insects were reared in net cages with $40 \mathrm{~cm}$ x $60 \mathrm{~cm}$ clear plastic tubs containing 50L of water, with high quality water hyacinth

132 plants, and incubated in a growth chamber at $25^{\circ} \mathrm{C}$. Damaged plants were replaced regularly with fresh healthy plants. Two morphological and two physiological traits and one index were

134 determined for the insects studied.

\section{Plant production}

136 Water hyacinth plants were procured in August 2013 from stock cultures maintained at high

137 levels of nitrogen in Waainek Mass Rearing Facility and a new culture was established at the

138 Department of Zoology and Entomology. To provide plants of 3 different nutrient qualities,

139 mother plants were grown in $40 \mathrm{~cm}$ x $60 \mathrm{~cm}$ plastic tubs filled with 50L of tap water adjusted

140 to three nitrogen concentration levels, as described in Ismail et al. (2017). There were 6 tubs of 
141 oligotrophic (low quality, tap water only), mesotrophic (medium quality: $1.5 \mathrm{mg} \mathrm{l}^{-1}$ ), and

142 eutrophic (high quality: $6.25 \mathrm{mg} \mathrm{l}^{-1}$ ) waters, based on nitrogen concentrations (Reddy et al., 143 1989). A water-soluble commercial fertilizer (Multifeed Classic Fertilizer, 19N: 8P: 16K) was

144 used in combination with a commercial iron chelate $\left(33 \mathrm{mg} \mathrm{l}^{-1}\right)$ to prevent chlorosis. The 145 selected concentrations are the averages of nitrogen levels reflecting the range present in South 146 African water bodies (Coetzee \& Hill, 2012). Water in the tubs with high, medium and low 147 nutrient levels was replaced every two weeks. Plants grown under high nutrient levels had large 148 green leaves of good quality and were judged to be eutrophic. Plants that were grown under 149 medium nutrient levels had smaller leaves just starting to yellow, and were considered to be 150 mesotrophic. Oligotrophic conditions produced plants of poor quality with small, yellow leaves

151 (Figure 1) (Ismail et al., 2017).

152

\section{Experimental design}

154 For the experiments, nymphs at the last stage were taken randomly from the insect culture and 155 placed individually in small plastic Petri dishes $(20 \mathrm{~mm})$ with moist filter paper and a fresh 156 water hyacinth leaf (replaced if necessary) until the adult stage.

157 The insects were exposed to 9 treatments, varying temperature against plant quality. Insects 158 were kept at 3 different temperatures $\left(20^{\circ}, 25^{\circ}\right.$ and $\left.30^{\circ} \mathrm{C}\right)$ and were fed on 3 qualities of plants 159 (high, medium and low) produced from mother plants. $30^{\circ} \mathrm{C}$ was considered a stressful 160 temperature since fitness traits were decreased significantly compared to 25 and $20^{\circ} \mathrm{C}$ (Ismail $161 \&$ Brooks, 2016).

162 One-day-old adult male and female E. eichhorniae were placed in pairs for two days at $25^{\circ} \mathrm{C}$ in small plastic Petri dishes $(20 \mathrm{~mm})$ with moist filter paper and a small fresh water hyacinth leaf

164 from each of the three water nutrient levels from the tub cultures, in order to become 165 reproductively mature. Sexual male and female pairs (the parental generation) were then 
166 transferred to individual clear plastic bottles (1L) each containing a young, 5 leaved water

167 hyacinth plant, with replicates for each of the three different qualities. Bottles were placed in 3

168 incubators at the 3 different temperatures (Binder GmbH, KBW 240 (E5.1), Tuttlingen,

169 Germany) with a thermal precision of $\pm 1^{\circ} \mathrm{C}$, under a photoperiod of $14 \mathrm{~L}$ : $10 \mathrm{D}$, and humidity

$17075 \pm 10 \%$. There were 9 replicates for each treatment, totaling 81 altogether. Fresh plants of the

171 respective plant quality were provided regularly to the nymphs resulting from these adult

172 pairings until they reached the adult stage.

173

174 Development time and Body indices

175 The development time of the progeny was calculated from the day the eggs were laid until the

176 individuals became adults.

177 In this study two morphological traits representing body size, tibia length and wing length, were

178 measured. Tibia length is the most common indicator of body size in insect parasitoids

179 (Godfray, 1994) and the forewing length is the most commonly used measure of body size in

180 Lepidoptera (Miller, 1977), damselfly (Hassall et al., 2008), mosquitoes (Siegel et al., 1994)

181 and Drosophila species (Liefting et al., 2009). A previous study of E. eichhorniae (then referred

182 to as E. catarinensis) showed that tibia length was similar in females and males, while in

183 females the wings were longer than in males (Ismail \& Brooks, 2018).

184 Measurements for body indices were from 10 individuals (five males and five females) taken

185 randomly from the bottles at each replicate of the 9 combinations (temperature * food quality),

186 totaling 45 individuals of each sex for each combination. Body size was measured using the

187 numeric image analysis software Olympus Stream Motion 1.9 (Olympus Soft Imaging

188 Systems) under a binocular microscope (Olympus SZX-16) linked to a video camera (Olympus

189 DP 72), as follows: the length of the hind tibia (from the femur-tibia joint to the tibia-tarsus 
190 joint) and the length of the forewing (from base to the apex). The wing loading index was

191 calculated as the ratio of total body fresh mass to squared wing length (Gilchrist \& Huey, 2004).

The physiological traits (dry body mass and lipid content)

194 A total of 135 females and 135 males aged < 04 hours ( 15 female and 15 male individuals from

195 each of the nine treatments) were killed using liquid nitrogen, in order to immediately halt all 196 metabolic processes. Individuals were then frozen at $-20{ }^{\circ} \mathrm{C}$ until all replicates were processed.

197 Lipid content was determined based on the method explained in Visser and Ellers, (2012) and

198 Visser et al., (2010). Fresh mass of each mirid was recorded, after which they were freeze-dried

199 for 2 days (VirTis Benchtop 2 K freeze drier: SP Industries, USA) before measuring dry body

200 mass (DBM) of each mirid. Freeze-dried mirids were then placed individually in glass tubes 201 containing $5 \mathrm{ml}$ of ether. After one day the ether was removed, individuals were washed with a 202 fresh batch of ether and freeze-dried for 2 days, after which final dry weight (lean dry mass 203 LDM) was recorded. Body fat mass (FM) was derived by subtracting LDM from DBM, and

204 lipid content (LC) was calculated as a proportion (LC=FM/LDM). All mass measurements were 205 taken using a micro-electrobalance (Sartorius MC 598648-003-48, sensitivity 0.001 mg; 206 Goettingen, Germany) located in an isolated balance room.

Statistical analysis

209 Statistical analyses were conducted using the statistical software R version 4.0.2 (2020-06-22)

210 (R Core Team, 2020). Development times for males and females were analysed using 211 generalised linear model (GLM) with temperature and plant quality as fixed factors (Gamma 212 distribution with time data). GLM with temperature and plant quality as fixed factors, was also 213 used to analyse the other parameters: hind and wing length for females and males (Gamma 214 distribution), wing loading of males (quasibinomial distribution), wing loading of females, 
215 DBM for females and males (Gaussian distribution). We used ANCOVA to test the differences

216 in LC in males and females (data were square root transformed), with temperature and food 217 quality as the main factors and incorporating DBM as a covariate. Finally, the previous 218 parameters were further analysed to test the differences between females and males using GLM 219 with sex as a fixed factor. Significant results at $p<0.05$ were followed by the use of Tukey's 220 honest significant difference test for multiple comparison using the multcomp package and glht 221 function (Hothorn et al., 2008).

RESULTS

\section{Development time}

The development time from egg to the adult stage increased significantly with the combination of low plant quality and high temperatures at $25^{\circ}$ and $30^{\circ} \mathrm{C}$, compared to the combination of medium and high qualities of plant for both sexes (Table 1, Figure 2). Development time decreased significantly with increasing temperature (Table 1) and with high plant quality for both sexes (Table 1). Development time did not vary between females and males (Table 2).

\section{Hind tibia length}

232 A significant interaction was found between temperature and plant quality for both females and males (Table 1). Individuals reared on low quality food under $30^{\circ} \mathrm{C}$ had the smallest tibia length

234 (Figure $3 \mathrm{~A}, \mathrm{~B}$ ). Individuals grew significantly larger as judged by tibia length at low 235 temperature than at high temperature for both sexes (Table 1). Individuals of both sexes were 236 significantly bigger when reared on high quality plants than on low quality plants (Table 1). 237 Females and males had almost the same length of tibia (Table 2). 
A significant interaction was found between temperature and plant quality on wing length especially for females only (Table 1). Female individuals fed on low quality plants under $30^{\circ} \mathrm{C}$ presented the smallest wings and those fed on high quality plants at $20^{\circ} \mathrm{C}$ had the longest wing (Figure $3 \mathrm{C}$ ). Wing length decreased significantly in response to high temperature and to

244 low plant quality for both females and males (Table 1, Figure 3 C, D). Females had significantly 245 longer wings than males (Table 2).

Wing loading

248 A significant interaction was found between the two factors for females, but not for males

249 (Table 1). While females had greater wing loading when feeding on high quality plants at $30^{\circ} \mathrm{C}$, 250 they had lower wing loading when feeding on low quality plants at the same temperature 251 (Figure 4). Temperature had no significant effect on wing loading of E. eichhorniae for both sexes (Table 1). Plant quality had a significant impact on wing loading for females and males (Table 1), with greater wing loading when feeding on high quality food compared to low quality food (Figure 4). No significant difference was found between females and males (Table 2).

Dry body mass

No significant interaction was found between temperature and plant quality in females (Table 1), whereas a significant interaction was found between the two factors in males (Table 1). Male individuals feeding on high quality plants at $20^{\circ} \mathrm{C}$ had larger DBM (Figure $5 \mathrm{~B}$ ). Dry body mass 260 of individuals decreased significantly with increasing temperature for both sexes (Table 1, 261 Figure 5 A, B). Greater DBM was recorded in individuals fed on good quality food compared to those with poor food quality for both females and males (Table 1, Figure 5 A, B). Dry body mass of females was significantly higher than that of males (Table 2). 
266 There was no interaction between temperature and plant quality on LC in females or males

267 (Table 3). A positive correlation was detected between DBM and LC in females, but not in males (Table 3). Individuals of both sexes presented significantly greater LC at low temperature compared to high temperature (Table 3, Figure 5 C, D). Females tended to contain significantly more LC when fed on high quality plants than on plants of poor quality, but this was not the case for males (Figure 5 C, D). No difference in LC was observed between males and females (Table 2).

\section{DISCUSSION}

In this study, individuals of E. eichhorniae were exposed to contrasting abiotic and biotic factors: different temperatures and plant qualities. Development time was affected by temperature and plant quality. Tibia and wing length, dry body mass and lipid content decreased significantly with increasing temperature and reduced food quality in both sexes. Wing loading, in contrast, decreased significantly with low plant quality, and this response was more marked in females than in male individuals. In addition, the combined factors presented two types of synergistic effects on the same traits. When optimal factors were combined (ie. high plant quality and low temperature), positive synergistic effects were demonstrated on development time and tibia length of both females and males, wing length of females as well as dry body mass of males. On the other hand, when the stressor factors were combined (ie. low plant quality and high temperature), negative synergistic effects operated on the aforementioned traits. prediction 1, support the TSR (Atkinson, 1994; Atkinson \& Sibly, 1997; Angilletta \& Dunham, 2003). The smaller size at high temperature in our study might be related to the greater consumption of plant material (Niesenbaum \& Kluger, 2006), resulting in decreased efficiency 
of conversion of food into body matter, because of higher metabolic losses (Kingsolver \&

291 Woods, 1998). It can be argued that small size might be an adaptive attribute to cope with the effect of high temperatures, reducing the surface area of the insect, and hence the rate of evaporation from the body. In addition, the reduction of evaporation from individual bodies is considered to be a consequence of decreased cell size (Partridge et al., 1994; Partridge \& 295 French, 1996). These arguments are also consistent with the absolute energy demand hypothesis, which predicts that smaller individuals are at an advantage under stressful conditions (Blanckenhorn et al., 1995; Ismail et al., 2012). Smaller individuals may be able to withstand environmental stress because they require less energy to sustain their biological functions. Weldon et al. (2019) showed that smaller individuals of the marula fruit fly Ceratitis cosyra (Diptera: Tephritidae) had higher desiccation and starvation resistance than bigger ones. As foreseen in prediction 2, we found that individuals feeding on high quality plants developed faster and matured at larger size than those feeding on low quality plants. Body size for both sexes followed a linear pattern according to the quality of the plant at each tested temperature, confirming prediction 3. Thus, it appears that food of high quality is a major factor as a prerequisite for larger individuals, operating in a similar way to insect response to temperature in TSR. According to these results, we propose that further study may justify a food-size rule (FSR) equivalent to the TSR. A similar response of faster development time was found when nymphs of the Brazilian species E. catarinensis fed on high nutrient leaves comparing with those fed on low nutrient leaves (Burke et al., 2014). Mukarugwiro et al., (2018) demonstrated that larvae of Neochetina eichhorniae (Coleoptera: Curculionidae) have

311 larger body size and shorter larval developmental time when feeding on high quality plants of water hyacinth.

It is known that plant nutritional quality for insects is determined by the amino acid 314 concentration and composition of the phloem sap, as well as the ratio of total sugars (Abisgold 
et al., 1994; Simpson et al., 1995; Albittar et al., 2019). Both amino acids and sugars are linked

316 to nitrogen content in plants. Plant quality, however, varies during growth and development

317 because of many abiotic and biotic factors. For instance, nutritional quality of plants decreased

318 with increasing temperature (Bauerfeind \& Fischer, 2013) and depends on the levels of nutrients

319 in the environment in which they grow (Galloway et al., 2003). Thus, any change in the

320 nutritional quality of plants can influence the efficiency of converting ingested food into body

321 matter in insects. It has been shown that the efficiency of converting ingested food decreased

322 with decreasing quality of diet (Timmins et al., 1988). Previous studies showed that nitrogen

323 content of water hyacinth leaves increased with fertilizer treatments (Reddy et al., 1989;

324 Center \& Dray, 2010; Burke et al., 2014; Hill, 2014). It was also demonstrated that plant quality

325 of water hyacinth increased with increasing nitrogen content and decreasing the 326 carbon/nitrogen ratio (Burke et al., 2014; Hill, 2014), justifying our assumption that nitrogen

327 content, and consequently plant quality, of experimental plants increased with fertilizer 328 treatments (Figure 1).

In this study, we present evidence that the combination of two stressor effects, high

330 temperature and low plant quality, had greater synergistic negative effects, confirming

331 prediction 4 . Individuals reared at $30^{\circ} \mathrm{C}$ and fed on plants of differing quality, exhibited the

332 smallest size on poor quality plants. A consequence of smaller body size of adults for successive

333 generations continuing to feed on plants of lower quality, particularly at high temperature,

334 would be the reduction in fitness traits of the individuals. Indeed, individuals of E. eichhorniae

335 (then referred to as E. catarinensis) presented the lowest reproduction and survival rate of

336 immature individuals when exposed to the combined effect of high temperature and low plant 337 quality (Ismail et al., 2017). This also confirms findings that a combination of multiple 338 environmental factors had a greater negative impact on fitness traits of individuals as well as 
populations, than one factor alone (Scherber et al., 2013; Sulmon et al., 2015; Feehan et al., 340 2018).

341 Furthermore, reduced plant quality may affect the TSR. The protracted development 342 time of immature mirid individuals in our study in response to low quality plant when combined 343 with higher temperature might be due to the requirement for greater quantities of food when it 344 is of poor quality. This would necessitate more time spent on feeding, yet still yield a smaller 345 size. Importantly, extended time taken to reach the adult stage may be necessary in order to 346 maximize the rate of nutrient uptake from low quality plants (Taylor, 1988), due to decreased 347 conversion efficiency of digestive enzymes (Lindroth et al., 1991). Diamond and Kingsolver 348 (2010) found that a stressful combination of high temperature and low dietary quality could 349 reverse the temperature-size rule. They found that the pupal mass of the moth $M$. sexta was 350 higher when feeding on devil's claw than feeding on tobacco at $30^{\circ} \mathrm{C}$. Our study is the first to make these comparisons by using different qualities of the same plant at three temperatures. The slight increase in wing loading with higher temperature results in the need to increase wing beat frequency, and this may serve as an adaptation to a warmer environment, as 354 it has the additional effect of reducing the impact of higher temperature by cooling the body 355 (Mani, 1968; Morin et al., 1999). On the other hand, the individuals responded to lower quality plant by having lower wing loading, which is associated with superior flying ability (Marden \& Chai, 1991; Gilchrist \& Huey, 2004; Moiroux et al., 2010), conforming to prediction 5. Having a low wing load would enable an insect to fly further. Ability to disperse over greater 359 distances would enable individuals to migrate further in search of higher quality plant, which 360 could have fitness consequences for themselves and their offspring. Our results indicate that 361 both sexes of E. eichhorniae would respond to lower food quality with a theoretical increase in 362 their flight capacity. This response has already been shown among aphids, where starvation due 363 to low plant quality is a significant factor affecting flight initiation (Walters \& Dixon, 1982; 
Parry, 2013). In contrast, Center \& Dray (2010) demonstrated that flight ability of two weevil species $N$. eichhorniae and N. bruchi was at the expense of reproduction when feeding on high quality of water hyacinth.

Smaller body size was directly linked with reduced lipid content for both sexes. While lipid content decreased with increasing temperature for both sexes, the response varied among females and males according to food quality. Females tended to accumulate significantly more lipids during immature stages when feeding on higher quality food rather than on poor quality food. Plant quality is an essential factor for accumulation of lipids in females, whereas for males, increased food quality does not necessarily result in increased lipid content. This may be related to the fact that females need more energy than males, to sustain biological activities such as egg production and maturation (Bonduriansky, 2001; Ismail et al., 2012). Insect body fat plays an essential role in energy storage and utilization, as well as in multiple metabolic activities (Law \& Wells, 1989; Arrese \& Soulages, 2010). Therefore, low quality leaves may not provide sufficient nutrition to allow females to accumulate the quantity of lipids required to sustain all of their metabolic and energetic functions, including successful reproduction.

In conclusion, individuals attained greater size at maturity by feeding on plants of high quality and this relationship was linear at each tested temperature. However further investigations including other insect species would be essential to justify a food-size rule. These results demonstrate that plant quality could influence the relationship between development time and the TSR, particularly at increased temperatures. Plant quality interacting with temperature had positive or negative synergetic effects on the insects depending on whether the combination was optimal or stressful, respectively. Based on our results, the potential dispersal of individuals may depend on plant quality rather than temperature. Larger individuals of $E$. eichhorniae emerged when feeding on high quality plants at low temperature. However, since 
389 water hyacinth presents the biggest problem in eutrophic temperate areas, this may not 390 necessarily mean successful biological control. Small individuals feeding on high quality plants 391 at higher temperature may be more likely to stay, whereas smaller individuals emerging when 392 feeding on low quality plants at higher temperature, may have greater flying capability, 393 enabling them to disperse and thus limiting the population in the area of concern. In any of 394 these circumstances, re-release of larger individuals with greater reproductive efficiency due to 395 stored energy reserves may be advisable, as this would make the population more sustainable, 396 and so help to assure the success of biological control. 


\section{ACKNOWLEDGMENTS}

401 This study was supported by funding from Rhodes University, as well as from the South African 402 Research Chairs Initiative of the Department of Science and Technology, and the National 403 Research Foundation of South Africa. We thank Shirley Pinchuck and Marvin Randall for 404 facilitating work at the Electron Microscope Unit. 
406 CONFLICT OF INTEREST: The authors declare that they have no conflict of interest.

407

408 AUTHOR CONTRIBUTION

409 MI conceived research, conducted the experiments and analysed data. MI, MB, JB and LA

410 wrote and approved the manuscript

411

412

DATA AVAILABILITY STATEMENT

413 The data that support the finding of this study is available on Mendeley:

414 (http://dx.doi.org/10.17632/pnj7247t7n.1\#file-742dd7fe-e22b-49fc-98b4-1f3ecc4db0c8)

415

416 


\section{REFERENCES}

418 Abisgold, J.D., Simpson, S.J. \& Douglas, A.E. (1994) Nutrient regulation in the pea aphid 419 Acyrthosiphon pisum: application of a novel geometric framework to sugar and amino acid 420 consumption. Physiological Entomology, 19, 95-102.

421 Albittar, L., Ismail, M., Lohaus, G., Ameline, A., Visser, B., Bragard, C., et al. (2019) Bottom422 up regulation of a tritrophic system by Beet yellows virus infection: consequences for aphid423 parasitoid foraging behaviour and development. Oecologia, 191, 113-125.

424 Angilletta, M.J. \& Dunham, A.E. (2003) The temperature-size rule in ectotherms: Simple 425 evolutionary explanations may not be general. American Naturalist, 162, 332-342.

426 Angilletta, M.J., Steury, T.D. \& Sears, M.W. (2004) Temperature, growth rate, and body size 427 in ectotherms: Fitting pieces of a life-history puzzle. Integrative and Comparative Biology, $\mathbf{4 4 ,}$ $428 \quad 498-509$.

429 Arrese, E.L. \& Soulages, J.L. (2010) Insect fat body: energy, metabolism, and regulation. $430 \quad$ Annual Review of Entomology, 55, 207-225.

431 Atkinson, D. (1994) Temperature and organism size - a biological law for ectotherms. In 432 Advances in Ecological Research, Vol 25, Advances in Ecological Research. pp. 1-58.

433 Atkinson, D. \& Sibly, R.M. (1997) Why are organisms usually bigger in colder environments?

434 Making sense of a life history puzzle. Trends in Ecology \& Evolution, 12, 235-239.

435 Awmack, C.S. \& Leather, S.R. (2002) Host plant quality and fecundity in herbivorous insects. 436 Annual Review of Entomology, 47, 817-844.

437 Bauerfeind, S.S. \& Fischer, K. (2013) Increased temperature reduces herbivore host-plant 438 quality. Global Change Biology, 19, 3272-3282.

439 Beukeboom, L.W. (2018) Size matters in insects - an introduction. Entomologia 440 Experimentalis et Applicata, 166, 2-3. 
Blanckenhorn, W.U. (1998) Adaptive phenotypic plasticity in growth, development, and body

442 size in the yellow dung fly. Evolution, 52, 1394-1407.

443 Blanckenhorn, W.U. (1999) Different growth responses to temperature and resource limitation

444 in three fly species with similar life histories. Evolutionary Ecology, 13, 395-409.

445 Blanckenhorn, W.U., Fanti, J. \& Reim, C. (2007) Size-dependent energy reserves, energy 446 utilization and longevity in the yellow dung fly. Physiological Entomology, 32, 372-381.

447 Blanckenhorn, W.U., Preziosi, R.F. \& Fairbairn, D.J. (1995) Time and energy constraints and 448 the evolution of sexual size dimorphism - to eat or to mate. Evolutionary Ecology, 9, 369-381. 449 Bonduriansky, R. (2001) The evolution of male mate choice in insects: a synthesis of ideas and 450 evidence. Biological Reviews, 76, 305-339.

451 Bownes, A., Hill, M.P. \& Byrne, M.J. (2013) Nutrient-mediated effects on Cornops aquaticum 452 Bruner (Orthoptera: Acrididae), a potential biological control agent of water hyacinth, 453 Eichhornia crassipes (Mart.) Solms (Pontederiaceae). Biological Control, 67, 548-554.

454 Burke, A.M., Coetzee, J.A. \& Hill, M.P. (2014) Effect of nutrient quality and leaf age of water 455 hyacinth, Eichhornia crassipesEichhornia crassipes, on the development of its co-evolved 456 herbivore, Eccritotarsus catarinensis (Hemiptera: Miridae). African Entomology, 22, 896-899. 457 Center, T.D. \& Dray, A. (2010) Effects of host quality on flight muscle development in 458 Neochetina eichhorniae and N. bruchi (Coleoptera: Curculionidae). Florida Entomologist, 93. 459 Chown, S.L. \& Gaston, K.J. (2010) Body size variation in insects: a macroecological 460 perspective. Biological Reviews, 85, 139-169.

461 Chown, S.L. \& Terblanche, J.S. (2006) Physiological Diversity in Insects: Ecological and 462 Evolutionary Contexts. Advances in insect physiology, 33, 50-152.

463 Coetzee, J.A. \& Hill, M.P. (2012) The role of eutrophication in the biological control of water 464 hyacinth, Eichhornia crassipesEichhornia crassipes, in South Africa. Biocontrol, 57, 247-261. 
465 Diamond, S.E. \& Kingsolver, J.G. (2010) Environmental Dependence of Thermal Reaction

466 Norms: Host Plant Quality Can Reverse the Temperature-Size Rule. American Naturalist, 175, $467 \quad 1-10$.

468 Ellers, J., Alphen, J.J.M. van \& Sevenster, J.G. (1998) A field study of size-fitness relationships 469 in the parasitoid Asobara tabida. Journal of Animal Ecology, 67, 318-324.

470 Feehan, C.J., Ludwig, Z., Yu, S. \& Adams, D.K. (2018) Synergistic negative effects of thermal 471 stress and altered food resources on echinoid larvae. Scientific Reports, 8, 12229.

472 Galloway, J.N., Aber, J.D., Erisman, J.W., Seitzinger, S.P., Howarth, R.W., Cowling, E.B., et 473 al. (2003) The nitrogen cascade. Bioscience, 53, 341-356.

474 Gaston, K.J. \& Lawton, J.H. (1988) Patterns in the distribution and abundance of insect 475 populations. Nature, 331, 709.

476 Gilchrist, G.W. \& Huey, R.B. (2004) Plastic and genetic variation in wing loading as a function 477 of temperature within and among parallel clines in Drosophila subobscura. Integrative and 478 Comparative Biology, 44, 461-470.

479 Godfray, H.C.J. (1994) Parasitoids: behavioral and evolutionary ecology. Princeton University 480 Press, Princeton.

481 Hassall, C., Thompson, D.J. \& Harvey, I.F. (2008) Latitudinal variation in morphology in two 482 sympatric damselfly species with contrasting range dynamics (Odonata: Coenagrionidae). 483 European Journal of Entomology, 105, 939-944.

484 Haunerland, N.H. (1997) Transport and utilization in insect flight muscles. Comparative 485 Biochemistry and Physiology B-Biochemistry \& Molecular Biology, 117, 475-482.

486 Hill, J.M. (2014) Investigations of growth metrics and $\delta 15 \mathrm{~N}$ values of water hyacinth 487 (Eichhornia crassipesEichhornia crassipes, (Mart.) Solms-Laub) in relation to biological 488 control. Aquatic Botany, 114, 12-20. 
Hill, M.P., Center, T.D., Stanley, J., Cordo, H.A., Coetzee, J.A. \& Byrne, M.J. (2000) The

490 performance of the water hyacinth mirid, Eccritotarsus catarinensis, on water hyacinth and 491 pickerel weed: a comparison of laboratory and field results. In The Xth International Symposium 492 on the Biological Control of Weeds 4-14 July, 1999 (ed. by Spencer, N.R.). Montana State 493 University, pp. 357-366.

494 Hill, M.P., Cilliers, C.J. \& Neser, S. (1999) Life history and laboratory host range of 495 Eccritotarsus catarinensis (Carvalho) (Heteroptera : Miridae), a new natural enemy released on 496 water hyacinth (Eichhornia crassipes (Mart.) Solms-Laub.) (Pontederiaceae) in South Africa. Biological Control, 14, 127-133.Henry T. J. (2017).

Description of a cryptic new species of the plant bug genus Eccritotarsus (Heteroptera: Miridae:

Bryocorinae) from Peru, a new biocontrol agent of water hyacinth, Eichhornia crassipes 500 (Pontederiaceae). Proceedings of the Entomological Society of Washington, 119, 398-407. http://doi.org/10.4289/0013-8797.119.3.398

Hogendorp, B.K., Cloyd, R.A. \& Swiader, J.M. (2006) Effect of nitrogen fertility on 503 reproduction and development of citrus mealybug, Planococcus citri Risso (Homoptera:

504 Pseudococcidae), feeding on two colors of coleus, Solenostemon scutellarioides L. Codd. 505 Environmental Entomology, 35, 201-211.

506 Honek, A. (1993) Intraspecific variation in body size and fecundity in insects - a general 507 relationship. Oikos, 66, 483-492.

508 Hothorn, T., Bretz, F. \& Westfall, P. (2008) Simultaneous Inference in General Parametric 509 Models. Biometrical Journal, 50, 346-363.

510 Ismail, M. \& Brooks, M. (2016) The impact of geographical origin of two strains of the 511 herbivore, Eccritotarsus catarinensis, on several fitness traits in response to temperature. 512 Journal of Thermal Biology, 60, 222-230. 
513 Ismail, M. \& Brooks, M. (2018) Male mating preference of two cryptic species of the

514 herbivorous insect Eccritotarsus catarinensis. Biocontrol Science and Technology, 529-543.

515 Ismail, M., Compton, S.G. \& Brooks, M. (2017) Interaction between temperature and water 516 nutrient levels on the fitness of Eccritotarsus catarinensis (Hemiptera: Miridae), a biological 517 control agent of water hyacinth. Biological Control, 106, 83-88.

518 Ismail, M., Vernon, P., Hance, T. \& Baaren, J. van. (2010) Physiological costs of cold exposure 519 on the parasitoid Aphidius ervi, without selection pressure and under constant or fluctuating 520 temperatures. Biocontrol, 55, 729-740.

521 Ismail, M., Vernon, P., Hance, T., Pierre, J.S. \& Baaren, J. van. (2012) What are the possible 522 benefits of small size for energy-constrained ectotherms in cold stress conditions? Oikos, 121, $523 \quad 2072-2080$

524 Kingsolver, J.G. \& Huey, R.B. (2008) Size, temperature, and fitness: three rules. Evolutionary 525 Ecology Research, 10, 251-268.

526 Kingsolver, J.G., Izem, R. \& Ragland, G.J. (2004) Plasticity of size and growth in fluctuating 527 thermal environments: Comparing reaction norms and performance curves. Integrative and 528 Comparative Biology, 44, 450-460.

529 Kingsolver, J.G. \& Woods, H.A. (1998) Interactions of temperature and dietary protein concentration in growth and feeding of Manduca sexta caterpillars. Physiological Entomology, $531 \quad 23,354-359$.

532 Kogel, W.J. de, Bosco, D., Hoek, M. van der \& Mollema, C. (1999) Effect of host plant on 533 body size of Frankliniella occidentalis (Thysanoptera: Thripidae) and its correlation with 534 reproductive capacity. European Journal of Entomology, 96, 365-368.

535 Kraushaar, U. \& Blanckenhorn, W.U. (2002) Population variation in sexual selection and its 536 effect on size allometry in two dung fly species with contrasting sexual size dimorphism. 537 Evolution, 56, 307-321. 
538 Lacoume, S., Bressac, C. \& Chevrier, C. (2006) Effect of host size on male fitness in the 539 parasitoid wasp Dinarmus basalis. Journal of Insect Physiology, 52, 249-254.

540 Law, J.H. \& Wells, M.A. (1989) Insects as biochemical models. Journal of Biological 541 Chemistry, 264, 16335-16338.

542 Lee, K.P., Jang, T., Ravzanaadii, N. \& Rho, M.S. (2015) Macronutrient balance modulates the 543 temperature-size rule in an ectotherm. American Naturalist, 186, 212-222.

544 Liefting, M., Hoffmann, A.A. \& Ellers, J. (2009) Plasticity versus environmental canalization: 545 population differences in thermal responses along a latitudinal gradient in Drosophila serrata. 546 Evolution, 63, 1954-1963.

547 Lindroth, R.L., Barman, M.A. \& Weisbrod, A.V. (1991) Nutrient deficiencies and the gypsy

548 moth, Lymantria dispar: effects on larval performance and detoxification enzyme activities.

549 Journal of Insect Physiology, 37, 45-52.

550 Mani, M.S. (1968) Ecology and Biogeography of High Altitude Insects. Junk Publishers, The 551 Hague.

552 Marden, J.H. \& Chai, P. (1991) Aerial predation and butterfly design: how palatability, mimicry 553 and the need for evasive flight constrain mass allocation. American Naturalist, 138, 15-36.

554 Masclaux, Hé., Bec, A., Kainz, M.J., Desvilettes, C., Jouve, L. \& Bourdier, G. (2009) 555 Combined effects of food quality and temperature on somatic growth and reproduction of two 556 freshwater cladocerans. Limnology and Oceanography, 54, 1323-1332.

557 Mega, N.O. (2014) The adult body size variation of Dryas iulia (Lepidoptera, Nymphalidae, 558 Heliconiinae) in different populations is more influenced by temperature variation than by host559 plant availability during the seasons. Entomological Science, 17, 376-387.

560 Miller, W.E. (1977) Wing measure as a size index in lepidoptera - family Olethreutidae. Annals 561 of the Entomological Society of America, 70, 253-256. 

Entomology, 26, 373-396.

564 Moiroux, J., Le Lann, C., Seyahooei, M.A., Vernon, P., Pierre, J.-S., Van Baaren, J., et al. 565 (2010) Local adaptations of life-history traits of a Drosophila parasitoid, Leptopilina boulardi: 566 does climate drive evolution? Ecological Entomology, 35, 727-736.

567 Morin, J.P., Moreteau, B., Petavy, G. \& David, J.R. (1999) Divergence of reaction norms of 568 size characters between tropical and temperate populations of Drosophila melanogaster and $D$ 569 simulans. Journal of Evolutionary Biology, 12, 329-339.

Mukarugwiro, J. d'Arc, Newete, S., Hauptfleisch, K. \& Byrne, M. (2018) The effect of water nutrients on the feeding intensity and development of larvae of Neochetina eichhorniae 572 (Warner) (Coleoptera: Curculionidae), a biocontrol agent of the invasive water hyacinth. African Entomology, 26, 63-72 . http://doi.org/10.4001/003.026.0063.

574

575
Musundire, R., Chabi-Olaye, A. \& Krueger, K. (2012) Host plant effects on morphometric characteristics of Liriomyza huidobrensis, L. sativae and L. trifolii (Diptera: Agromyzidae). Journal of Applied Entomology, 136, 97-108.

Niesenbaum, R.A. \& Kluger, E.C. (2006) When studying the effects of light on herbivory, should one consider temperature? The case of Epimecis hortaria F. (Lepidoptera: Geometridae) feeding on Lindera benzoin L. (Lauraceae). Environmental Entomology, 35, 600-606.

Nylin, S. \& Gotthard, K. (1998) Plasticity in life-history traits. Annual Review of Entomology, 43, 63-83.

Parry, H.R. (2013) Cereal aphid movement: general principles and simulation modelling. Movement ecology, 1, 14-14.

Partridge, L., Barrie, B., Fowler, K. \& French, V. (1994) Evolution and development of body size and cell size in Drosophila melanogaster in response to temperature. Evolution, 48, 12691276. 
Partridge, L. \& French, V. (1996) Thermal evolution of ectotherm body size: why get big in the cold? In Animals and temperature: phenotypic and evolutionary adaptation (ed. by Johnston, I.A. \& Bennett, A.F.). Cambridge University Press, Cambridge, pp. 265-292.

Paterson, I.D., Coetzee, J.A., Weyl, P., Griffith, T.C., Voogt, N. \& Hill, M.P. (2019) Cryptic species of a water hyacinth biological control agent revealed in South Africa: host specificity, 592 impact, and thermal tolerance. Entomologia Experimentalis et Applicata, 167, 682-691.

593 Paterson, I.D., Mangan, R., Downie, D.A., Coetzee, J.A., Hill, M.P., Burke, A.M., et al. (2016) 594 Two in one: cryptic species discovered in biological control agent populations using molecular 595 data and crossbreeding experiments. Ecology and Evolution, 6, 6139-6150.

596 R. Core Team. (2020) R: A language and environment for statistical computing. R Foundation 597 for Statistical Computing. Vienna, Austria. ISBN 3-900051-07-0, URL http://www.R598 project.org/.

599 Reddy, K.R., Agami, M. \& Tucker, J.C. (1989) Influence of nitrogen supply rates on growth 600 and nutrient storage by water hyacinth (Eichhornia crassipes) plants. Aquatic Botany, 36, 3360143.

602 Rivero, A. \& West, S.A. (2002) The physiological costs of being small in a parasitic wasp. 603 Evolutionary Ecology Research, 4, 407-420.

604 Roff, D.A. (1992) The evolution of life histories: theory and analysis. Chapman and Hall, 605 London.

606 Scherber, C., Gladbach, D.J., Stevnbak, K., Karsten, R.J., Schmidt, I.K., Michelsen, A., et al. 607 (2013) Multi-factor climate change effects on insect herbivore performance. Ecology and 608 Evolution, 3, 1449-1460.

609 Siegel, J.P., Novak, R.J. \& Ruesink, W.G. (1994) Relationship between wing length and dry 610 weight of mosquitoes. Journal of the American Mosquito Control Association, 10, 186-196. 
611 Simpson, S.J., Abisgold, J.D. \& Douglas, A.E. (1995) Response of the pea aphid 612 (Acyrthosiphon pisum) to variation in dietary levels of sugar and amino acids: the significance 613 of amino acid quality. Journal of Insect Physiology, 41, 71-75.

614 Stamp, N.E. (1993) A temperate region view of the interaction of temperature, food quality, 615 and predators on caterpillar foraging. In Caterpillars: ecological and evolutionary constraints 616 on foraging (ed. by Stamp, N.E. \& Casey, T.M.). Chapman \& Hall, New York, pp. 478-508.

617 Stearns, S.C. (1992) The Evolution of Life Histories. Oxford University Press, Oxford.

618 Stillwell, R.C., Wallin, W.G., Hitchcock, L.J. \& Fox, C.W. (2007) Phenotypic plasticity in a 619 complex world: interactive effects of food and temperature on fitness components of a seed 620 beetle. Oecologia, 153, 309-321.

621 Sulmon, C., Baaren, J. van, Cabello-Hurtado, F., Gouesbet, G., Hennion, F., Mony, C., et al. 622 (2015) Abiotic stressors and stress responses: What commonalities appear between species 623 across biological organization levels? Environmental Pollution, 202, 66-77.

624 Taylor, M.F.J. (1988) Field measurement of the dependence of life history on plant nitrogen 625 and temperature for a herbivorous moth. Journal of Animal Ecology, 57, 873-891.

626 Timmins, W.A., Bellward, K., Stamp, A.J. \& Reynolds, S.E. (1988) Food intake, conversion 627 efficiency, and feeding behaviour of tobacco hornworm caterpillars given artificial diet of 628 varying nutrient and water content. Physiological Entomology, 13, 303-314.

629 Visser, B. \& Ellers, J. (2012) Effects of a lipid-rich diet on adult parasitoid income resources 630 and survival. Biological Control, 60, 119-122.

631 Visser, B., Le Lann, C., Blanken, F.J. den, Harvey, J.A., Alphen, J.J.M. van \& Ellers, J. (2010) 632 Loss of lipid synthesis as an evolutionary consequence of a parasitic lifestyle. Proceedings of 633 the National Academy of Sciences of the United States of America, 107, 8677-8682. 
634 Visser, M.E. (1994) The importance of being large - the relationship between size and fitness 635 in females of the parasitoid Aphaereta minuta (Hymenoptera, Braconidae). Journal of Animal 636 Ecology, 63, 963-978.

637 Walters, K.F.A. \& Dixon, A.F.G. (1982) The effect of host quality and crowding on the settling 638 and take-off of cereal aphids. Annals of Applied Biology, 101, 211-218.

639 Weldon, C.W., Mnguni, S., Démares, F., Rand, E.E. du, Malod, K., Manrakhan, A., et al. (2019) 640 Adult diet does not compensate for impact of a poor larval diet on stress resistance in a tephritid 641 fruit fly. The Journal of Experimental Biology, 222, jeb192534.

642 
644 Table 1. Results of GLM for the effects of temperature and plant quality and their interaction 645 on the measured parameters of the herbivore Eccritotarsus eichhorniae. Significant effects are 646 in bold.

\begin{tabular}{|c|c|c|c|c|c|c|c|}
\hline & & & Fema & & & Males & \\
\hline Parameter & Factor & df & $\mathrm{F}$ & $\mathrm{P}$ & df & $\mathrm{F}$ & $\mathrm{P}$ \\
\hline Development time (Days) & Temperature & 2 & 1865.77 & $<0.001$ & 2 & 1774.022 & $<0.001$ \\
\hline & Plant quality & 2 & 39.11 & $<0.001$ & 2 & 35.78 & $<0.001$ \\
\hline & Interaction & 4 & 19.10 & $<0.001$ & 4 & 20.43 & 0.001 \\
\hline & Residuals & 169 & & & 169 & & \\
\hline Tibia length (mm) & Temperature & 2 & 75.42 & $<0.001$ & 2 & 155.47 & $<0.001$ \\
\hline & Plant quality & 2 & 62.66 & $<0.001$ & 2 & 27.14 & $<0.001$ \\
\hline & Interaction & 4 & 5.77 & $<0.001$ & 4 & 4.74 & $<0.001$ \\
\hline & Residuals & 396 & & & 396 & & \\
\hline Wing length (mm) & Temperature & 2 & 141.71 & $<0.001$ & 2 & 148.45 & $<0.001$ \\
\hline & Plant quality & 2 & 51.97 & 0.001 & 2 & 20.03 & 0.001 \\
\hline 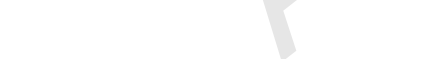 & Interaction & 4 & 2.66 & 0.03 & 4 & 1.36 & 0.24 \\
\hline & Residuals & 326 & & & 300 & & \\
\hline Wing loading & Temperature & 2 & 0.37 & 0.68 & 2 & 0.97 & 0.38 \\
\hline & Plant quality & 2 & 9.21 & $<0.001$ & 2 & 7.76 & $<0.001$ \\
\hline & Interaction & 4 & 2.62 & 0.03 & 4 & 1.51 & 0.20 \\
\hline & Residuals & 126 & & & 126 & & \\
\hline
\end{tabular}




$\begin{array}{llcccccr}\text { DBM (mg) } & \text { Temperature } & 2 & 39.41 & <\mathbf{0 . 0 0 1} & 2 & 47.65 & <\mathbf{0 . 0 0 1} \\ & \text { Plant quality } & 2 & 41.4 & <\mathbf{0 . 0 0 1} & 2 & 73.25 & <\mathbf{0 . 0 0 1} \\ & \text { Interaction } & 4 & 1.07 & 0.37 & 4 & 2.62 & \mathbf{0 . 0 3} \\ & \text { Residuals } & 126 & & & 126 & \end{array}$

647

648 
649 Table 2.

650 Results of GLM for the effect of sex on the measured parameters of the herbivore Eccritotarsus

651 eichhorniae. Significant effects are in bold.

652

\begin{tabular}{lccc}
\hline & df & F & P \\
\hline Development time (Days) & 1,354 & 0 & $<\mathbf{0 . 0 0 1}$ \\
Tibia length (mm) & 1,808 & 0.54 & 0.46 \\
Wing length (mm) & 1,643 & 39.66 & $<\mathbf{0 . 0 0 1}$ \\
Wing loading & 1,268 & 3.47 & 0.06 \\
DBM (mg) & 1,268 & 22.57 & $<\mathbf{0 . 0 0 1}$ \\
LC & 1,268 & 0.03 & 0.86 \\
\hline
\end{tabular}

653

654 
655 Table 3. ANCOVA with the effects of temperature and plant quality and their interaction

656 (temperature $\mathrm{x}$ plant quality) and with dry body mass as a covariate, on lipid content of the 657 herbivore Eccritotarsus eichhorniae. Significant effects are in bold.

658

\begin{tabular}{llcccccc}
\hline & & \multicolumn{3}{c}{ Females } & \multicolumn{3}{c}{ Males } \\
\hline Parameter & Factor & df & F & P & df & F & P \\
\hline LC & Temperature & 2 & 11.06 & $<\mathbf{0 . 0 0 1}$ & 2 & 13.39 & $<\mathbf{0 . 0 0 1}$ \\
& Plant quality & 2 & 8.19 & $<\mathbf{0 . 0 0 1}$ & 2 & 1.60 & 0.20 \\
& Interaction & 4 & 0.11 & 0.97 & 4 & 1.04 & 0.38 \\
& DBM & 1 & 13.42 & $<\mathbf{0 . 0 0 1}$ & 1 & 0.63 & 0.42 \\
& Residuals & 125 & & & 125 & &
\end{tabular}

659

660

661 


\section{$663 \quad$ Figure 1}

664 Three plants of water hyacinth that were grown under high (a), medium (b) and low (c)

665 nutrient levels..

666

667 Figure 2

668 Development time in days for females and males of Eccritotarsus eichhorniae reared at three temperatures $\left(20,25\right.$ and $\left.30^{\circ} \mathrm{C}\right)$, and fed on three qualities of plant (high, medium and low).

670 Small letters indicate the significant interaction between temperature and plant quality for both 671 sexes.

672

$673 \quad$ Figure 3

674 Tibia length (A, B) and wing length (C, D) for both females and males of Eccritotarsus 675 eichhorniae, reared at three temperatures and fed on three qualities of plant (high, medium and 676 low). In figures (A, B and C) small letters indicate the significant interaction between the two 677 factors and represent the differences among the treatments for both sexes. In Figure (D) small 678 letters indicate the significant differences among the different qualities of plant. Capital letters 679 indicate the significant difference among different temperatures.

680

$681 \quad$ Figure 4

682 Wing loading for both females and males of Eccritotarsus eichhorniae reared at three 683 temperatures $\left(20,25\right.$ and $\left.30^{\circ} \mathrm{C}\right)$, and fed on three qualities of plant (high, medium and low). For 684 males, small letters indicate the significant difference among the different qualities of plant. For 685 females, small letters indicate the significant interaction between temperature and plant quality 686 and represent the differences among the treatments. 


\section{$687 \quad$ Figure 5}

688 Dry body mass (A and B) and lipid content (C and D) of females and males of Eccritotarsus 689 eichhorniae reared at three temperatures and fed on three qualities of plant (high, medium and 690 low). In figures (A, C and D) small letters indicate the significant differences among the 691 different qualities of plant. Capital letters indicate the significant difference among different 692 temperatures. In Figure (B) small letters indicate the significant interaction between 693 temperature and plant quality and represent the differences among the treatments.

694 
695 Figure 1

696

697
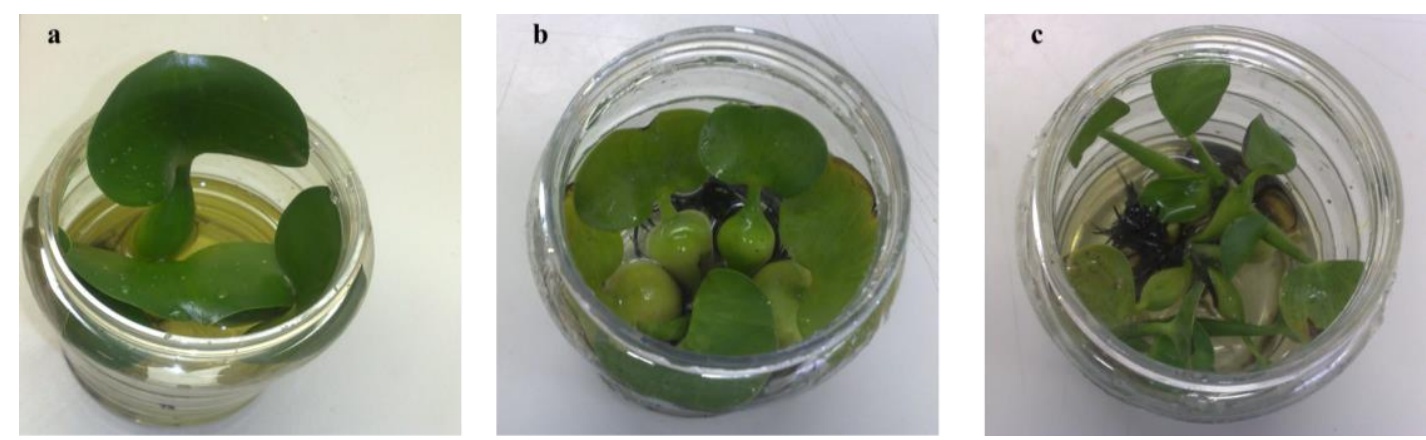
698 Figure 2

699

700

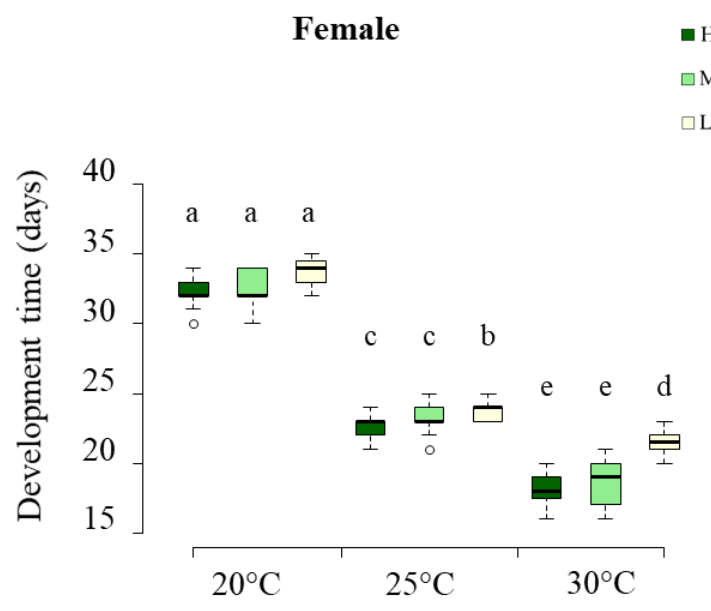

— High nutrient

Male

Medium nutrient

Low nutrient

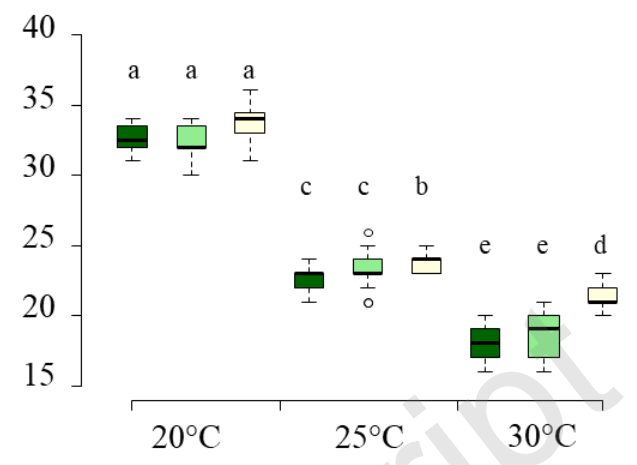

701

702

703

704 
$705 \quad$ Figure 3
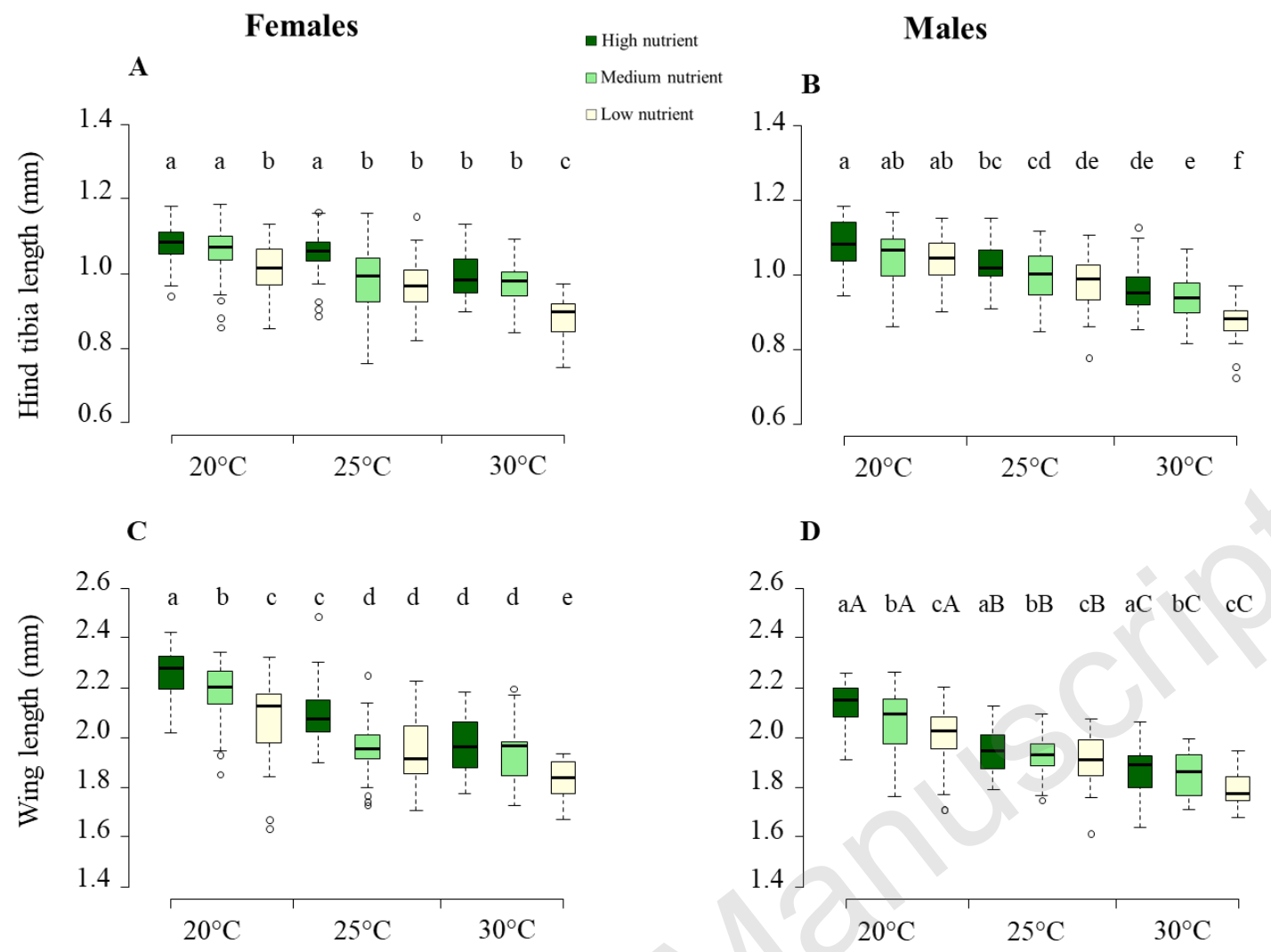

D

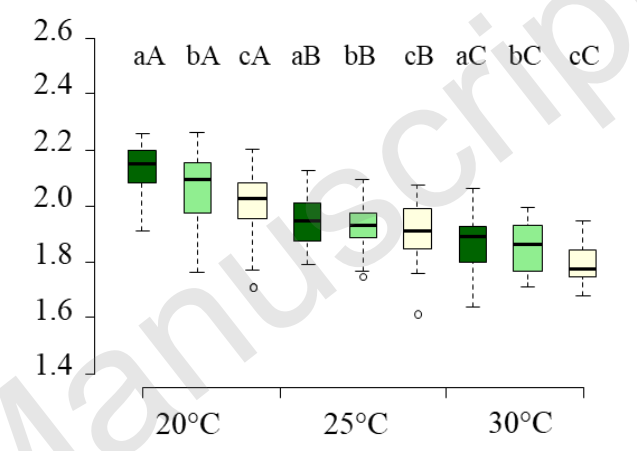

706

707

708 
Figure 4

710

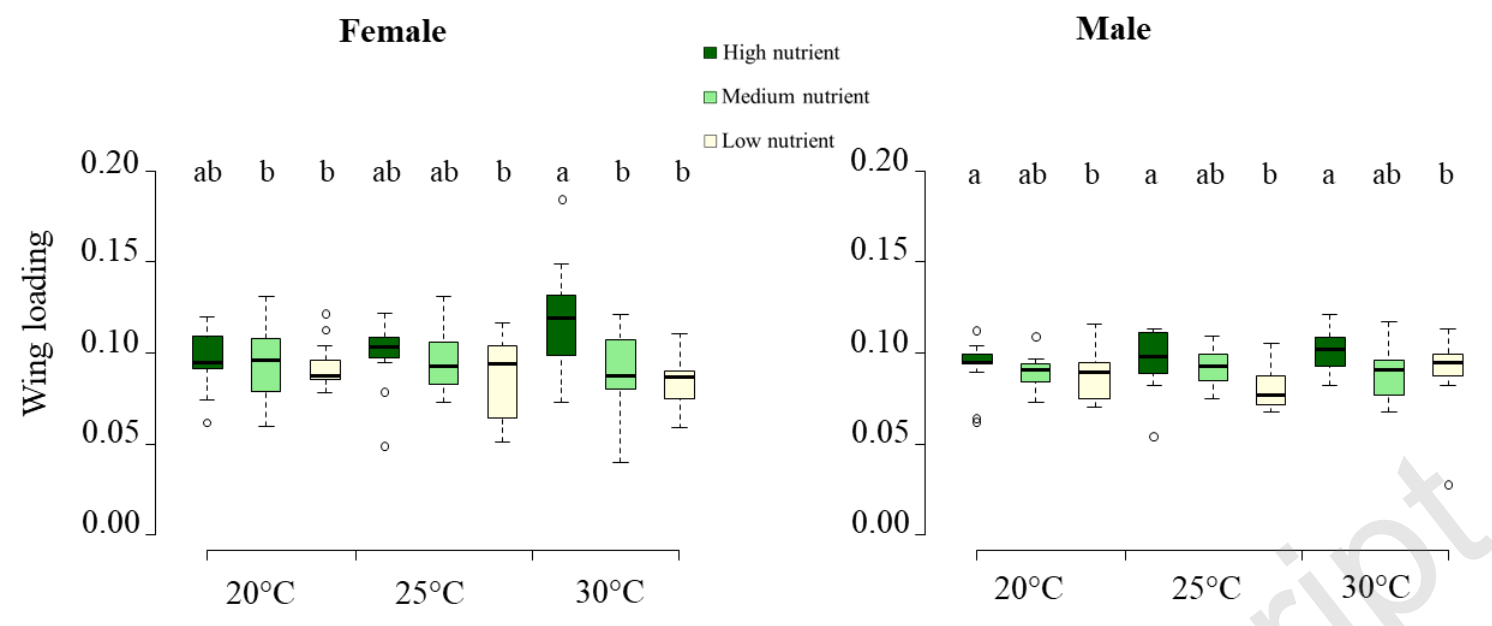

711

712

713 
714 Figure 5
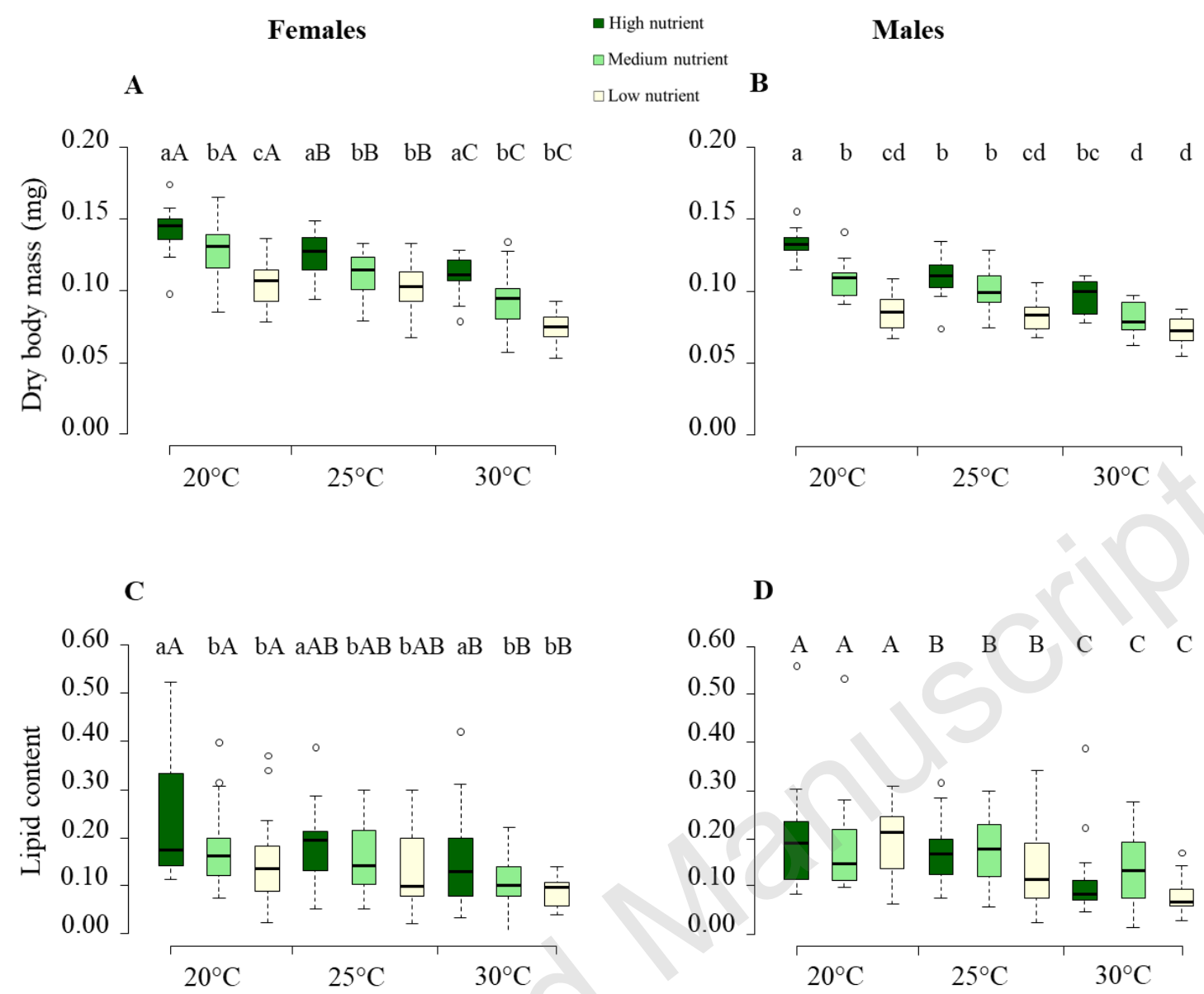

D

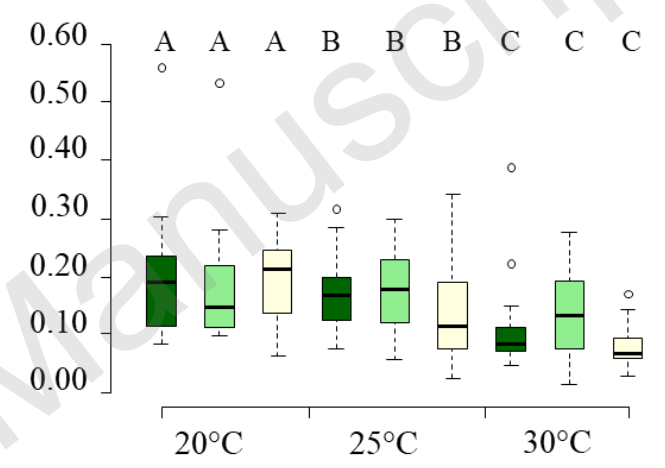

716 